Caries Res. 1967;1:370-371

\title{
Subject Index Vol. 1
}

Absorption, intestinal, of sugars, 187

Acid production, from carbohydrates in plaque, 78

Activation analysis, of enamel antimony, 327

-, - carbon, 318

Amino acids, in enamel protein, 349

Antimony, in human enamel 327

Bell's palsy and caries, 162 Biopsy, of enamel, 153

Calcium, binding to glycoprotein,

343 -, in enamel, 137 -, in parotid saliva, 333 - polyphosphates, in enamel and

dentine, 1 Carbohydrates, and acid formation

in plaque, 78 -, and dental findings, 222 -, and nutrition, economy and

caries, 185 Carbon dioxide, in enamel, 137 -, in human enamel, 318 Caries, after Bell's palsy, 162 -, and carbohydrates, 185 -, and infant feeding, 167 -, artificial, with dark zone, 261 -, with dark zone, 261 Cariogenicity, of starch, 208 -, of sucrose, 208

Dark zone in caries, 261 Density patterns in enamel, 42

Dentinal fluid, hydrodynamics, 310 Digestion of sugars, 187

Enamel, amino acid content, 349

- $\quad$ antimony, determination, 327

-, biopsy, 153

-, $\quad$ calcium content, 137

-, $\quad$ carbon, determination, 318

-, $\quad$ - dioxide content, 137

- $\quad$ caries, electron microscopy, 356

-, $\quad$ density patterns, 42

-, mineralisation, micro-chemical

investigation, 174 -, nitrogen content, 137 -, phosphorus content, 137 -, sodium content, 137 -, wear, 32 Enzymes, affection by fluorine

compounds, 69

Facial paralysis and caries, 162 Fermentative capabilities of

plaques, 247 Fluoridated water, F determination, 295 Fluoride, and enamel wear, 32 -, and sugar, effect on plaque $\mathrm{pH}$,

130 -, determination in enamel, 153 -, determination in water, 295 -, determination methods, 295 -, isolation by micro-diffusion, 281 -, radioactive, use in biology, 299,

309 Fluorine compounds, effects on enzymes, 69

Subject Index

371

Glycoprotein, salivary, Ca-binding, 343

Incisor caries and infant feeding, 167

Magnesium, in parotid saliva, 333 Maturation, of rat enamel hypo- 
plasia, 15 Microbes, in plaques, 239 Micro-diffusion, for fluoride

isolation, 281 Mineralisation, of pig enamel, 174 Molybdate, and sugar, effect on

plaque $\mathrm{pH}, 130$ Monofluorophosphate, biologic

splitting, 144

Nitrogen, in enamel, 137

Organic films on teeth, composition, 89

$\mathrm{pH}$ measurement, on monkey teeth, 59

Phosphorus, in enamel, 137 Plaque, fermentative capabilities,

247 -, microbes, 239 Polyphosphates, in enamel and

dentine, 1 Pulp fluid, hydrodynamics, 310 Saliva, Mg and Ca secretion, 333 Salivary

glycoprotein, Ca-binding,

343

-, in enamel integuments, 104

proteins, adsorption to hydro-xylapatite, 52

Sodium, in enamel, 137 Starch, cariogenicity, 208 Sucrose, cariogenicity, 208 Sugars, intestinal digestion and absorption, 187

Triazines, and caries, 275

Wear, of deciduous enamel, 32 -, of enamel, and fluoride content, 32 